WHAT THEN IS THE PROBLEM?

So, what is the problem? The problem is that not all patients are helped by our current treatments either because of drug intolerance and toxicity or lack of response. Additionally, complete remission, defined as no painful and no swollen joints, is rarely seen and the ability to stop background disease modifying treatment without eliciting a flare is an exceptional event.

Given the high cost of the biological agents some of our patients may also have difficulty obtaining these effective treatments. As the popularity of biological response modifiers increases there is concern that the insurance carriers or healthcare authorities may institute policies to restrict their use further, which will limit access to this class of drugs.

In the United States an attempt to restrict access could be reflected first in higher drug co-payments-that is, the amount the patients must themselves pay to receive treatment. For a patient who is now responsible for $10 \%$ of the annual cost of the drug which increases to $20 \%$ for anti-TNF treatment, the annual cost would increase from $\$ 1500$ to over $\$ 3000$, which in many cases would make this treatment unaffordable.

In Europe, healthcare authorities may restrict access by limiting further the number of patients who can receive such treatment.

Are patients satisfied with where they are now? If you ask patients what they want from treatment the responses are wide ranging: improved disease activity and function, less pain, a cure, less drug toxicity, and stable and affordable drug pricing. Is this much different from what we, as rheumatologists, would like to achieve? I think not!

\section{EVALUATION OF NEW TREATMENTS}

So how do we evaluate new treatments in the light of our current successes in RA treatment? Firstly, the science of performing clinical trials in RA has been refined and standardised. There are now validated end points for defining response rates, such as the ACR20 score and the EULAR DAS, validated measures of functional and quality of life instruments, and a consensus for scoring radiographic damage, which are accepted by investigators and the regulatory authorities for drug review and approval. These advances in the science of clinical trials in RA have increased our ability to evaluate new treatments for RA. In addition, unlike 20 years ago, when most studies of disease modifying treatments were performed in academic centres, clinical studies are now 
performed throughout the world in both academic and community based practices. This leads to more generalisable studies from a wider based study population and has allowed easier and more efficient subject recruitment.

\section{WHICH PATIENTS SHOULD BE STUDIED?}

Perhaps the answer to the question of the future of RA treatment should begin with a consideration of the best patient population to study. The easiest population to study now is the group of patients for whom anti-TNF treatments have failed. These patients represent the greatest challenge for the rheumatologist. However, many sponsors are reluctant to include these patients in the early phases of testing, because there is a concern that this particular cohort represents an inherently "refractory population".

\section{"Failure of anti-TNF treatment does not preclude response to other treatments"}

However, there are no data to support such a bias. A patient for whom antiTNF treatment fails may well respond to other treatments relying on a different mechanism of action. For example, there are reports of patients who when anti-TNF treatment has failed have favourable responses to abatacept (a costimulatory blockade molecule). ${ }^{12}$ In addition, results from the rituximab study of a similar population will be available soon and hopefully will also demonstrate a positive outcome.

Perhaps yet another population is of even greater interest than the group for whom anti-TNF treatment has failed. These are the majority of patients who are currently receiving disease modifying treatment that may include antiTNF treatment, but who still have some degree of active arthritis; in other words, the "partial responders". It is on this group that we may want to concentrate our greatest efforts because they represent the greatest unmet need.

How many patients in a rheumatology practice could qualify for enrolment in a new clinical trial using current study eligibility criteria (six or more painful and swollen joints and a raised erythrocyte sedimentation rate or $\mathrm{C}$ reactive protein)? Sokka and Pincus reported that fewer than $15 \%$ of patients in the Pincus practice would qualify for such a clinical trial, yet many of those patients could be characterised as "partial responders", never mind "in remission". ${ }^{13}$

A similar scenario exists at our centre where we have enrolled 900 patients in an RA registry called BRASS. Of those patients receiving MTX, which represents about $65 \%$ of our BRASS cohort, only $20 \%$ would currently qualify for a clinical study using the current disease activity measures, but very few are in remission. We need to redefine active disease for entry into our clinical studies so that we can study patients who are doing well but are far from being in remission.

\section{TRIAL DESIGN}

Another difficulty with designing trials now is the knowledge that radiographic damage can occur as early as 36 months after the onset of RA. Is it ethical to do placebo controlled monotherapy trials beyond 12-16 weeks in light of this knowledge? Another popular design is one in which chronic MTX is the background treatment and patients receive additionally either the study drug or placebo. In these studies the MTX dose is fixed and the study duration ranges from 24 to 104 weeks. Multiple studies show that the group receiving MTX plus placebo has greater radiographic progression over time. ${ }^{9}{ }^{10}{ }^{14}$ In light of this finding is it appropriate or ethical to enrol patients in 1 and 2 year controlled trials in which the MTX dose is kept constant, because many of these patients will incur radiographic progression by the end of the trial.

\section{"Radiographic damage can occur in the first few months, so is it ethical to have a placebo arm?"}

One solution to this problem is the active comparator study with a noninferiority outcome, in which patients are randomised to receive either an active comparator or the study drug with or without background MTX. Although this type of study would require a large number of patients because the sample size is calculated on the premise that the study drug is "non-inferior" to the active comparator, it would be easy to recruit for this study design-no placebo arm!! - and would alleviate the concern about radiographic progression, which is built into the methodology of current placebo controlled trials.

Another interesting design is the randomised withdrawal study, which was used quite successfully in the study of etanercept in juvenile RA. ${ }^{15}$ In this design all patients receive the study drug in the open initial dosing phase and then the best responders are randomised to receive the study drug or placebo in the second phase of the study with the primary end point being time to flare.
What about combining a new biological agent with anti-TNF treatment? Our experience to date with combining targeted biological treatments has not been reassuring. Limited efficacy and increased infection have been reported in two recent trials: one, the addition of anakinra (interleukin 1 receptor antagonist) plus etanercept, ${ }^{16}$ and the other, a recently completed trial of abatacept with background biological DMARDs. ${ }^{17}$ In another case, outside the field of rheumatology, the disturbing events resulting from the addition of $\beta$-interferon plus natalizumab give us pause for thought about the wisdom of using combination biological agents to treat RA. ${ }^{18} 19$

\section{SOME QUESTIONS REMAIN}

So we are still left with the question of how to design clinical trials for those patients who have had a positive response with MTX plus a biological agent but still continue to have some degree of active rheumatoid disease. Do we add the study drug to MTX plus the biological agent with the goal to replace the initial biological agent? Do we design the study to look at triple drug treatment in RA with the end point being ACR70 or remission? If we are to make advances we need to develop new trial designs in light of both the current successes and the existing limitations in study paradigms to developing new treatments for RA. I welcome the thoughts of my colleagues around the world on how to deal with this problem.

Ann Rheum Dis 2005;64:1529-1531. doi: 10.1136/ard.2005.045351

Correspondence to: DrM E Weinblatt, Brigham and Women's Hospital, 75 Francis Street Boston, MA 02115, USA; mweinblatt@ partners.org

Accepted 22 August 2005

Published Online First 26 August 2005

\section{REFERENCES}

1 Weinblatt ME, Coblyn JS, Fox DA, Fraser PA Holdsworth DE, Glass DN, et al. Efficacy of lowdose methotrexate in rheumatoid arthritis. N Engl J Med 1985;312:818-22.

2 Andersen PA, West SG, O'Dell JR, Via CS Claypool RG, Kotzin BL. Weekly pulse methotrexate in rheumatoid arthritis. Clinical and immunologic effects in a randomized, doubleblind study. Ann Intern Med 1985; 103:489-96.

3 Williams HJ, Willkens RF, Samuelson CO Jr, Alarcón GS, Guttadauria M, Yarboro C, et al. Comparison of low-dose oral pulse methotrexate and placebo in the treatment of rheumatoid arthritis. A controlled clinical trial. Arthritis Rheum 1985;28:721-30.

4 Van der Heide A, Jacobs JWG, Biilsma JWJ, Heurkens $A H$, van Booma-Frankfort $C$, van der Veen $M J$, et al. The effectiveness of early treatment with "second line" antirheumatic drugs. A randomized, controlled trial. Ann Intern Med 1996; 124:699-707.

5 Weinblatt ME. Rheumatoid arthritis: Treat now, not later! Ann Intern Med 1996;124:773-4. 
6 Möttönen T, Hannonen P, Leirisalo-Repo $M$, Nissilä $M$, Kautiainen $H$, Korpela $M$, et al. Comparison of combination therapy with single-drug therapy in early rheumatoid arthritis: a randomised trial. Lancet 1999;353:1568-73.

7 Boers M, Verhoeven AC, Markusse HM, Van de Laar MA, Westhovens R, Van Denderen JC, et al. Randomised comparison of combined step-down prednisolone, methotrexate and sulphasalazine with sulphasalazine alone in early rheumatoid arthritis. Lancet 1997;350:309-18.

8 Grigor C, Capell H, Stirling A, McMahon AD, Lock $P$, Vallance $R$, et al. Effect of a treatment strategy of tight control for rheumatoid arthritis (the TICORA study): a single-blind randomised controlled trial. Lancet 2004;364:263-9.

9 Klareskog L, Van der Heijde D, De Jager JP, Gough A, Kalden J, Malaise M, et al. Therapeutic effect of the combination of etanercept and methotrexate compared with each treatment alone in patients with rheumatoid arthritis: double-blind randomised controlled trial. Lancet 2004;363:675-81.

10 Breedveld FC, Kavanaugh AF, Cohen SB, Pavelka K, Van Vollenhoven R, Perez J, et al.
Early treatment of rheumatoid arthritis (RA) with adalimumab ( HUMIRA) plus methotrexate vs adalimumab alone or methotrexate alone or methotrexate alone: the Premier study [abstract]. Arthritis Rheum 2005;50(suppl):4096.

11 Pincus T, Sokka T, Kautiainen H. Patients seen for standard rheumatoid arthritis care have significantly better articular, radiographic, laboratory and functional status in 2000 than in 1985. Arthritis Rheum 2005;52:1009-19.

12 Genovese $M$, Luggen $M$, Schiff $M$, Sherrer $Y$, Nuamah I, Aranda R, et al. Efficacy and safety of abatacept (CTLA4lg), a selective co-stimulation modulator in rheumatoid arthritis patients not responding adequately to anti-TNF therapy: results of the phaselll ATTAIN trial [abstract] Arthritis Rheum 2004;50(suppl):4103.

13 Sokka T, Pincus T. Eligibility of patients in routine care for major clinical trials of anti-tumor necrosis factor agents in rheumatoid arthritis. Arthritis Rheum 2003;48:313-18.

14 Lipsky PE, van der Heijde DM, St Clair EW, Furst DE, Breedveld FC, Kalden JR, et al. Infliximab and methotrexate in the treatment of rheumatoid arthritis. N Engl J Med 2000:343:1594-602.
15 Lovell DJ, Giannini EH, Reiff A, Cawkwell GD, Silverman ED, Nocton JJ, et al. Etanercept in children with polyarticular juvenile rheumatoid arthritis. N Engl J Med 2000;342:763-9.

16 Genovese MC, Cohen S, Moreland L, Lium D Robbins S, Newmark R, et al. Combination therapy with etanercept and anakinra in the treatment of patients with rheumatoid arthritis who have been treated unsuccessfully with methotrexate. Arthritis Rheum 2004;50:1412-19.

17 Weinblatt M, Combe B, Aranda R, Becker J, Keystone E. Safety of abatacept in patients with active rheumatoid arthritis receiving background non-biologic and biologic DMARDs: 1 year results of the ASSURE trial (abstract). Annal Rheum Dis 2005;64(suppl):60.

18 Langer-Gould A Atlas SW, Green A Bollen AW, Pelletier D. Progressive multifocal leukoencephalopathy in a patient treated with natalizumab. N Engl J Med 2005;353:375-381

19 Kleinschmidt BK, Tyler KL. Progressive multifoca leukoencephalopathy complicating treatment with natalizumab and interferon beta- 1 a for multiple sclerosis. N Engl J Med 2005;353:369-374. 